\title{
GAS FoIL BEARING ANALYSIS AND THE EFFECT OF BUMP FoIL THICKNESS ON ITS PERFORMANCE CHARACTERISTICS USING A NON-LINEAR MATRIX EQUATION SOLVER
}

\author{
T. Moasunep. Jamir ${ }^{1)^{*}}$, S. K. Kakoty ${ }^{1)}$, Karuna Kalita ${ }^{1)}$ \\ ${ }^{1)}$ Department of Mechanical Engineering, \\ Indian Institute of Technology Guwahati. \\ Guwahati-781039, India. \\ *Corresponding author: sunepbokdi@gmail.com
}

\begin{abstract}
Gas foil bearings (GFBs) satisfy many of the requirements noted for novel oil-free turbomachinery. However, GFBs have a limited load carrying capacity. This paper presents a numerical model in order to assess the performance characteristics of gas foil bearings. The finite difference scheme has been used to discretize the governing Reynolds equation and the pressure is calculated by solving non-linear matrix equation using Newton-Raphson technique. The static performance analysis has been carried out. The computational analysis have been compared with the experimental and theoretical results available in the literature and the effects of bump foil thickness, number of bumps and bump compliance coefficient on the load carrying capacity at different rotor speed have been investigated. The results of the study show that too thin bump foil thickness may lead to a significant decrease in the load capacity. However for accurate predictions of the foil bearing performances, more details foil structure of $1 D$ and $2 D$ finite element model should be considered.
\end{abstract}

\section{KEYWORDS}

Gas Foil Bearings (GFBs), Newton-Raphson technique, bump foil thickness, bump foil compliance

\section{INTRODUCTION}

Gas foil bearings have been successfully used in various types of rotating machinery, such as turbochargers, auxiliary power units, and gas turbine engines. It offers several advantages over the conventional rigid surface bearings including higher load capacity, lower power loss and better stability. These advantageous characteristics of foil bearings have been demonstrated through many experimental investigations $[1-4]$.

The foil structure of a gas foil bearing consists of two parts: A smooth top foil that provides the bearing surface and a corrugated bump foil that provides resilient support for the top foil. Under the action of the hydrodynamic pressure, the foil structure deforms. This yields an appreciable change in the lubricant-film profile. Therefore, the fluid film pressure must be coupled to the deformation of the foil structure in order to ascertain the characteristics of the foil bearing 
performance. From this point of view, many analytical studies have been conducted based on a range of structural models.

Walowit and Anno [5] first presented an elastic model for a single bump, where in the bending and tensile stiffness of the bump were considered. This structural model was used by Heshmat et al. [6] in an investigation of the steady state behavior of a foil bearing. $\mathrm{Ku}$ and Heshmat [7, 8] also developed a theoretical model of the corrugated foil strip deformation introducing friction force between the bump foils and the bearing housing or top foil, and the effect of bump geometry on the foil strip compliance. An experimental procedure has been presented to investigate the foil strip deflection under static loads. Through an optical track system, bump deflection images are captured indicating that the horizontal deflection of the segment between bumps is negligible compared to the transversal deflection of the bumps. Rubio and San Andrés [9] also presented an experimental and analytical procedure aimed to identify the structural stiffness for an entire bump-type foil bearing. Ruscitto et al. [10] performed a series of load capacity tests of bump type GFBs. The static performance analysis of GFBs considering threedimensional shape of the foil structure was performed by Lee et al. [11]. Using this model, the deflections of interconnected bumps are compared to those of separated bumps, and the minimum film thickness is compared to those of previous models. In addition, the effects of the top foil and bump foil thickness on the foil bearing static performance are also evaluated. Lee et al. [12] studied operating characteristics of the bump GFBs considering top foil bending phenomenon and correlation among bump foils. Kim and San Andre's [13, 14] in comparisons with test data [10] validate a GFB model that implements the simple elastic foundation model with formulas for bump stiffness taken from [15]. They did analysis of GFBs integrating 1D and 2D FE top foil models. 2D FE model predictions overestimate the minimum film thickness at the bearing centreline, but slightly underestimate it at the bearing edges. Predictions from the 1D FE model compare best to the limited tests data, reproducing closely the experimental circumferential profile of minimum film thickness.

Several approaches have been put forward to calculate the steady state characteristics of gas foil bearings by different researchers. Keospel [16] developed a forward iteration method. Finite difference method has been used for solving the fluid model and finite element method has been used for the structural model. Heshmat et al. [6] has developed an inverse method where finite difference method has been used for solving fluid model and the structural model. A NewtonRaphson method has been used to solve the finite difference method. A modified forward iteration method has been put forwarded by Carpino and Peng [17] where finite element method has been used for both fluid model and structural model. Subsequently, this modified iteration method has been used by Carpino and Peng [17] for calculating steady state characteristics of gas foil bearings while calculating stiffness and damping coefficients for elastically supported gas foil bearings. Lee et al. [11] developed an iterative method for calculating the static performance analysis of foil journal bearings. A three dimensional model has been considered for the foil structure and finite element method has been used for solving fluid model and the three dimensional foil model.

In this paper finite difference method has been used to discretize the governing Reynolds equation. The discretized equation has been written in the form of a quadratic function for every node and Newton-Raphson technique have been used to solve the non-linear matrix equation. The steady state characteristic of the GFB are then assessed and the steady state characteristics results have been compared with the experimental and theoretical results available in the literature. The 
effects of various bearing parameters on the load carrying capacity of the bearing have been envisaged

\section{GAS FOIL BEARING DESCRIPTION}

\subsection{Governing Equations}

Figure 1 shows a schematic view of bump type GFB. The Reynolds equation describes the generation of the gas pressure (p) within the film thickness (h) and for an isothermal, isoviscous ideal gas this equation is,

$$
\frac{\partial}{\partial x}\left(p h^{3} \frac{\partial p}{\partial x}\right)+\frac{\partial}{\partial z}\left(p h^{3} \frac{\partial p}{\partial z}\right)=6 \mu \omega R \frac{\partial(p h)}{\partial x}+12 \mu \frac{\partial(p h)}{\partial t}
$$

where, $(x, z)$ are the circumferential and axial coordinates on the plane of bearing, . The pressure takes ambient value $p_{a}$ on the side boundaries of the bearing.

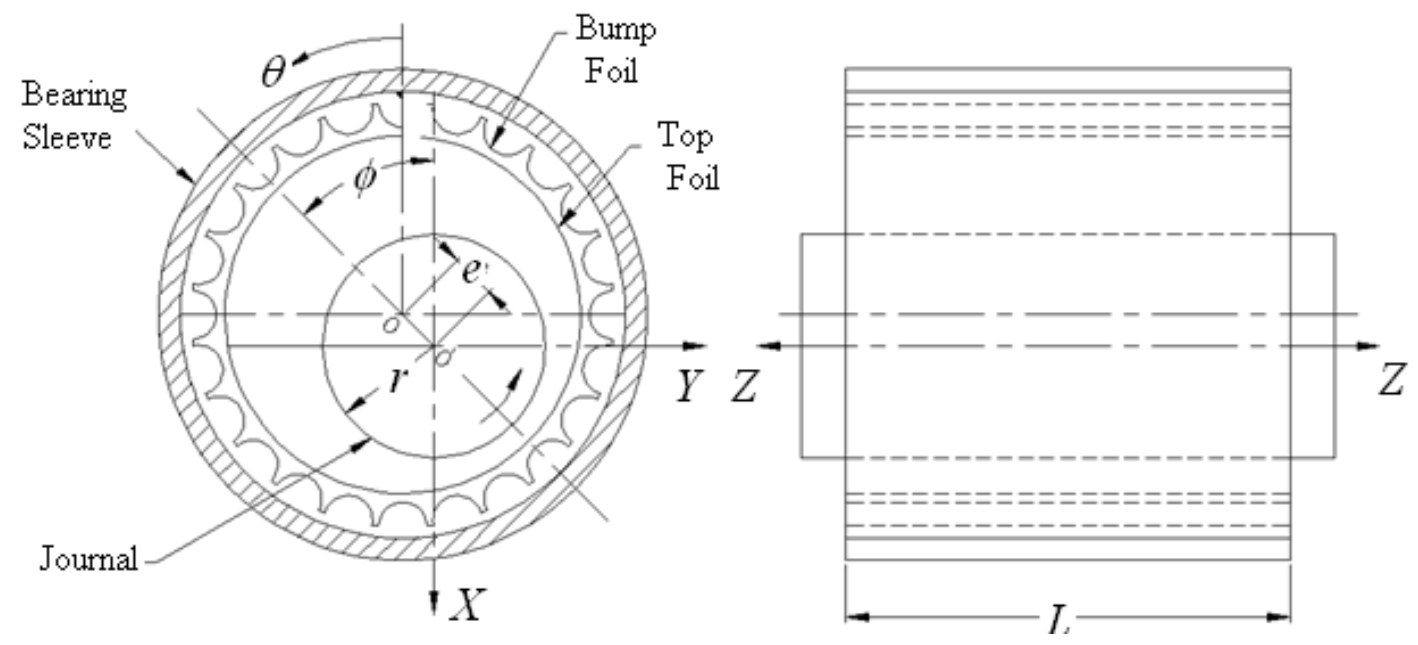

Fig.1 Schematic view of bump type GFB

The boundary conditions for the solution of Eqn. (1) are

$$
\begin{aligned}
& p=p_{a} \quad \text { at } \quad \theta=0 \text { and } 2 \pi \\
& p=p_{a} \quad \text { at } \quad z=0 \text { and } L
\end{aligned}
$$

The film thickness $(h)$ for a perfectly aligned journal configuration is given by

$$
h=c+e \cos (\theta-\phi)+w_{t}
$$

Where, $c, e$ and $w_{t}$ are the assembled clearance, journal eccentricity and the elastic deformation of the foil structure respectively. 
Therefore Eqn. (1) and Eqn. (3) are coupled through the hydrodynamic pressure and elastic deformation of the foil structure as a function of the hydrodynamic pressure.

The above governing equations can be normalized by using the following substitutions as follows:

$$
\begin{array}{lrrl}
S=\alpha p_{a} / C & H=h / C & z=Z / R & \frac{x}{R}=\theta \\
y=Y / L & P=\bar{p} / p_{a} & \varepsilon=e / C & W=w_{t} / C
\end{array}
$$

Hence steady state non-dimensional Reynolds equation as given in Eqn. (1) is given by

$$
-\frac{\partial}{\partial Z}\left(P H^{3} \frac{\partial P}{\partial Z}\right)-\frac{\partial}{\partial \theta}\left(P H^{3} \frac{\partial P}{\partial \theta}\right)+\Lambda \frac{\partial P H}{\partial \theta}=0
$$

where

$$
\Lambda=\left(6 \mu \omega / p_{a}\right)(R / C)^{2}
$$

And similarly the non-dimensional film thickness is given as,

$$
H=1+\varepsilon \cos (\theta-\phi)+W
$$

where $\varepsilon$ is the eccentricity ratio.

\subsection{Steady State Formulation of Reynolds Equation}

The non-dimensionalized Reynolds Eqn. (5) has been discretized using a finite difference approach. For all the derivatives present in Eqn. (5) central difference formula have been used. Figure 2 shows an exfoliated view of a bearing showing the mesh size $(\Delta \theta \times \Delta Z) . m$ and $n$ are the divisions along $\theta$ and $Z$ respectively. The dimension of the pressure in the domain in matrix form will be $(m+1) \times(n+1)$ represent by $\mathbf{P}$. The vector representation of $\mathbf{P}$ is $\mathbf{p}$ and its length is $(m+1)(n+1)$. Similarly foil deflection and film thickness in matrix forms are represented by $\mathbf{W}$ and $\mathbf{H}$ respectively. If $(i, j)$ is any arbitrary point in the matrix representation, its position in the vector representation can be written as $q=(j-1)(m+1)+i$. The four adjacent nodes associated with node $(i, j)$ are $(i+1, j),(i-1, j),(i, j+1)$ and $(i, j-1)$ as shown in Fig 2. The discretized form of equation (5) for $(i, j)^{\text {th }}$ node or $q^{\text {th }}$ node can be written in a quadratic form as

$$
\left(\mathbf{p}_{q}^{e}\right)^{T} \mathbf{A}_{q}^{e} \mathbf{p}_{q}^{e}+\mathbf{b}_{q}^{e} \mathbf{p}_{q}^{e}=\mathbf{0}
$$

where $\mathbf{p}_{q}^{e}=\left\{P_{(i, j-1)} \quad P_{(i-1, j)} \quad P_{(i, j)} \quad P_{(i+1, j)} \quad P_{(i, j+1)}\right\}^{T}$ and its size is $5 \times 1$, 
International Journal of Recent advances in Mechanical Engineering (IJMECH) Vol.3, No.3, August 2014

$$
\mathbf{A}_{q}^{e}=\left[\begin{array}{ccccc}
\frac{H_{(i, j-1)}^{3}}{4(\Delta Z)^{2}} & 0 & 0 & 0 & -\frac{H_{(i, j-1)}^{3}}{4(\Delta Z)^{2}} \\
0 & \frac{H_{(i-1, j)}^{3}}{4(\Delta \theta)^{2}} & 0 & -\frac{H_{(i-1, j)}^{3}}{4(\Delta \theta)^{2}} & 0 \\
\frac{H_{(i, j)}^{3}}{(\Delta Z)^{2}} & \frac{H_{(i, j)}^{3}}{(\Delta \theta)^{2}} & -\frac{2 H_{(i, j)}^{3}}{(\Delta \theta)^{2}}-\frac{2 H_{(i, j)}^{3}}{(\Delta Z)^{2}} & \frac{H_{(i, j)}^{3}}{(\Delta \theta)^{2}} & \frac{H_{(i, j)}^{3}}{(\Delta Z)^{2}} \\
0 & -\frac{H_{(i+1, j)}^{3}}{4(\Delta \theta)^{2}} & 0 & \frac{H_{(i+1, j)}^{3}}{4(\Delta \theta)^{2}} & 0 \\
-\frac{H_{(i, j+1)}^{3}}{4(\Delta Z)^{2}} & 0 & 0 & 0 & \frac{H_{(i, j+1)}^{3}}{4(\Delta Z)^{2}}
\end{array}\right]
$$

$\mathbf{A}_{q}^{e}$ is a $5 \times 5$ non-symmetric matrix,

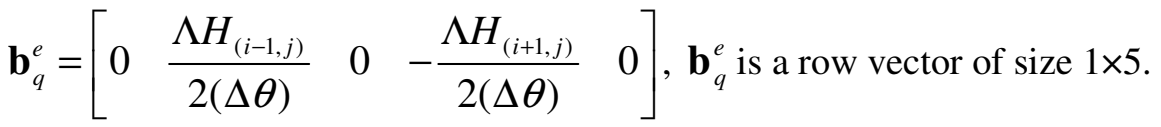

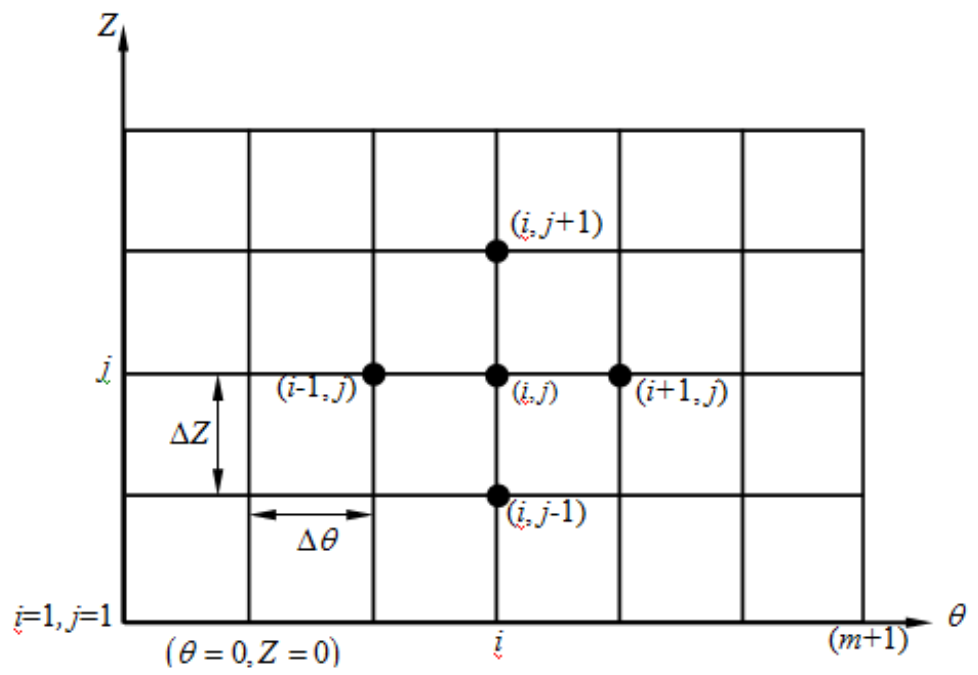

Fig. 2: An exfoliated view of a bearing showing the mesh size $(\Delta \theta \times \Delta Z)$

The force of the gas film acting on the journal can be computed by integrating the pressure over the bearing surface. According to the coordinate system illustrated in Fig. 3, this integration can be written as:

$$
\bar{W} x=-\int_{-L / D}^{L / D} \int_{0}^{2 \pi} P \cos \theta d \theta d Z
$$


International Journal of Recent advances in Mechanical Engineering (IJMECH) Vol.3, No.3, August 2014

$$
\bar{W} y=\int_{-L / D}^{L / D} \int_{0}^{2 \pi} P \sin \theta d \theta d Z
$$

For numerical integration, Simpson's one third rule has been used.

Finally the total non-dimensional load is given by

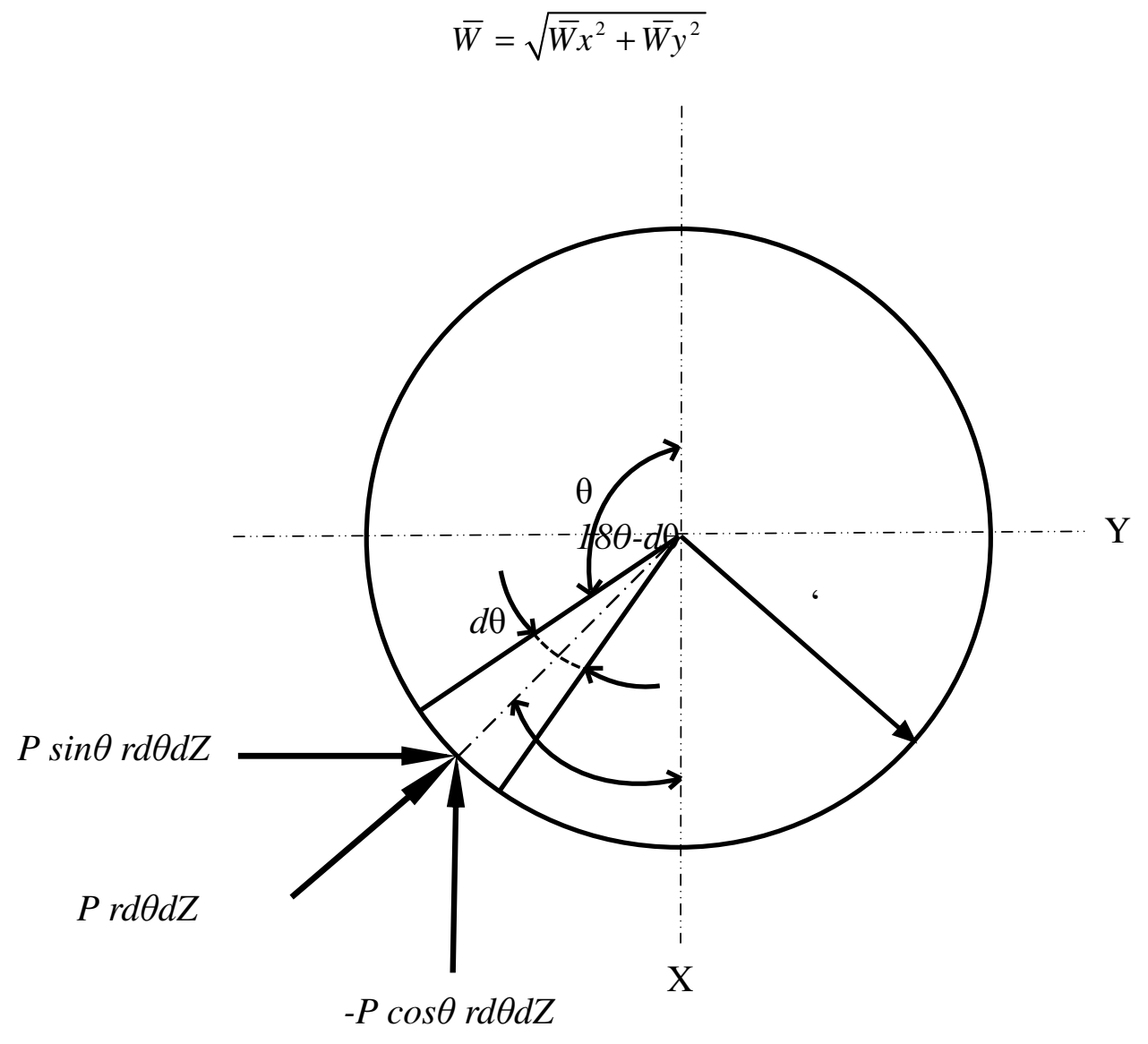

Fig. 3: The coordinate system and the sign convention of the journal forces

\section{SOLUTION METHOD}

In the present algorithm, a fixed coordinate system has been considered (X and $\mathrm{Y}$ ). Therefore, for steady state equilibrium, the horizontal load component should become zero. The flowchart of the solution process is shown in Fig. 4. For a given eccentricity ratio, the attitude angle is varied till the horizontal load component approximately becomes zero. Bisection method has been used for bracketing and also to calculate the correct attitude angle. The load capacity is simply equal to the vertical load component. Initially, the non-dimensional top foil deflection $\mathbf{W}$ is assumed as zero. To start with the iteration, the non-dimentionalised pressures at all the mesh points are assumed as 1 (i.e. ambient pressure) and those at the boundaries are also set to the ambient pressure. Newton-Raphson method has been used to solve the discretized Reynolds Eqn. (7) for 
air pressure $\mathbf{p}$ in this paper. Once the pressure is found out the non-dimensional top foil deflection $\mathbf{W}$ is calculated. After that, substituting the new value of non-dimensional top foil deflection $\mathbf{W}$ in the equation of film thickness, the quadratic equation is solved for all the mesh points to estimate the pressure at all these points. This quadratic equation would not be satisfied for the pressures which are assumed to be constant in the beginning. Hence, the iterative process is carried out until the following convergence criterion is satisfied.

$$
\frac{\left|\sum\left(\mathbf{p}^{(k-1)}\right)-\sum\left(\mathbf{p}^{(k)}\right)\right|}{\left|\sum\left(\mathbf{p}^{(k)}\right)\right|} \leq 10^{-6}
$$

\subsection{Newton-Raphson Method}

In order to apply Newton-Raphson method we define the residue vector $\mathbf{r}$ in Eqn. (7) as

$$
\mathbf{r}_{q}=\left(\mathbf{p}_{q}^{e}\right)^{T} \mathbf{A}_{q}^{e} \mathbf{p}_{q}^{e}+\mathbf{b}_{q}^{e} \mathbf{p}_{q}^{e} \quad \text { where } q=1,2, \ldots,(m+1)(n+1)
$$

where $\mathbf{r}_{q}$ is the residue vector for $q^{\text {th }}$ node and its length is $5 \times 1$. The length of the residue vector $\mathbf{r}$ is $(m+1)(n+1)$. The residue vector of the $q^{\text {th }}$ node for the $k$-th iteration is

$$
\left(\mathbf{r}_{q}^{e}\right)^{(k)}=\left[\left(\mathbf{p}_{q}^{e}\right)^{T}\right]^{(k)}\left(\mathbf{A}_{q}^{e}\right)^{(k)}\left(\mathbf{p}_{q}^{e}\right)^{(k)}+\left(\mathbf{b}_{q}^{e}\right)^{(k)}\left(\mathbf{p}_{q}^{e}\right)^{(k)} \quad \text { where } q=1,2, \ldots,(m+1)(n+1)
$$

The $q^{\text {th }}$ row of the sensitivity matrix, $\mathbf{G}$ is calculated as

$$
\left(\mathbf{G}_{q}\right)^{(k)}=\left[\left(\mathbf{p}_{q}^{e}\right)^{T}\right]^{(k)}\left[\left(\mathbf{A}_{q}^{e}\right)^{(k)}+\left\{\left(\mathbf{A}_{q}^{e}\right)^{T}\right\}^{(k)}\right]+\left(\mathbf{b}_{q}^{e}\right)^{(k)} \quad \text { where } q=1,2, \ldots,(m+1)(n+1)
$$

The size of the matrix $\mathbf{G}$ is $[(m+1)(n+1) \times(m+1)(n+1)]$. The pressure is updated as

$$
\mathbf{p}^{(k+1)}=\mathbf{p}^{(k)}-\lambda^{(k)}\left(\mathbf{G}^{-1}\right)^{(k)} \mathbf{r}^{(k)}
$$

where $\mathbf{p}^{(k+1)}$ and $\mathbf{p}^{(k)}$ are the pressures at $(k+1)^{\text {th }}$ and $k^{\text {th }}$ iterations respectively. $\mathbf{G}^{(k)}$ is the sensitivity matrix at $k^{\text {th }}$ iteration. $\lambda^{(k)}$ is the $k^{\text {th }}$ step length. The computation is stopped when the error between two successive iteration steps is smaller than $1 \times 10^{-6}$. 


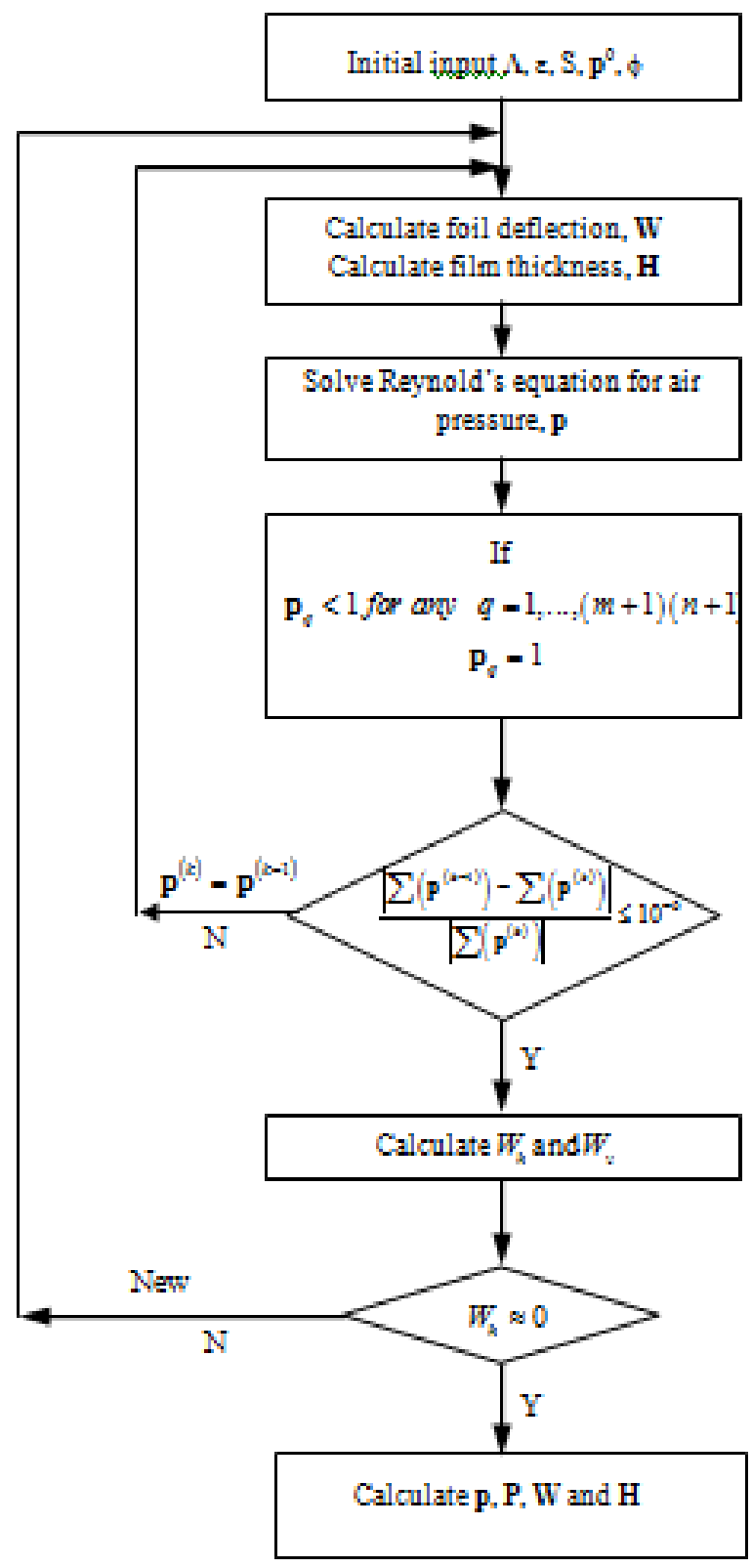

Fig. 4: Flowchart of solution algorithm

\section{MODELLING OF FOIL SUPPORT STRUCTURE}

The elastic support structure considered in the present analysis is a simple foundation model, the original work of Heshmat et al [6] which most of the published models are based on. This analysis relies on several assumptions which other researchers have also reproduce: 
(1) The stiffness of a bump strip is uniformly distributed throughout the bearing surface, i.e. the bump strip is regarded as a uniform elastic foundation.

(2) A bump stiffness is constant, independent of the actual bump deflection, not related to or constrained by adjacent bumps.

(3) The top foil does not sag between adjacent bumps. The top foil does not have either bending or membrane stiffness, and its deflection follows that of the bump

With this considerations, the deformation $\left(w_{t}\right)$ depends on the bump compliance $(\alpha)$ and the average pressure across the bearing width as shown Fig. 5,

$$
w_{t}=\alpha\left(\bar{p}-p_{a}\right)
$$

where, $\bar{p}$ and $\alpha$ are the arithmetic mean pressure in the axial direction and compliance of the bump foil.

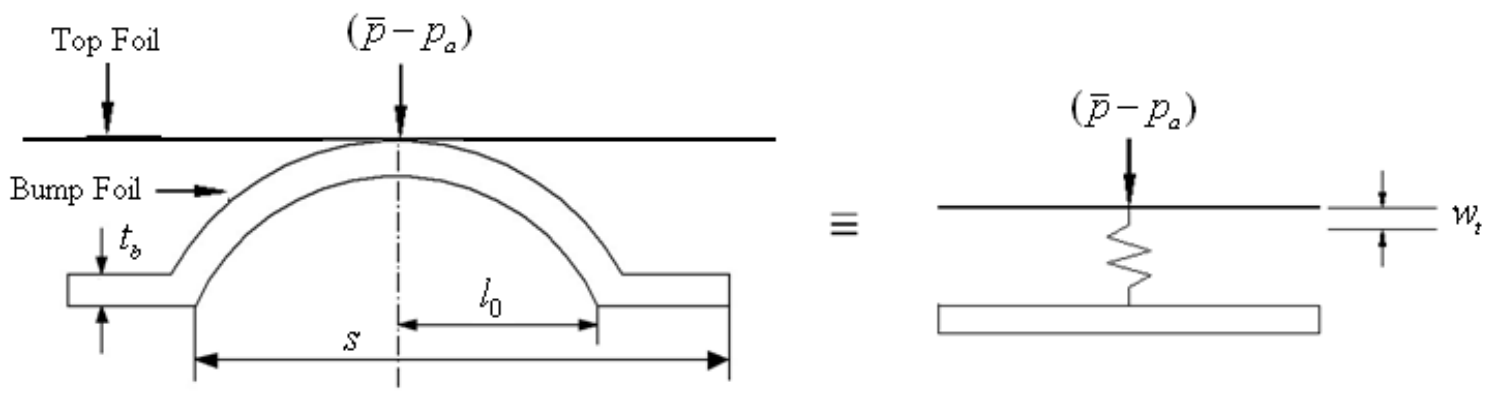

Fig.5 Single segment of Bump foil [18]

The dimensionless deflection of the bump is given by

$$
W=S(P-1)
$$

Coupling of the simple model equation (16) with the solution of Reynolds equation (5) is straightforward for the prediction of the static performance of GFBs.

\section{VALIDATION, RESULTS AND PREDICTIONS OF THE MODEL}

\subsection{Validation}

The validity of the present analysis and computational program are assessed by comparison of predictions with published data available in open literature. As shown in figure 6 and 7, the 
International Journal of Recent advances in Mechanical Engineering (IJMECH) Vol.3, No.3, August 2014

present computation analysis are assessed with Heshmat et al [6] and Peng and Carpino[5]. From the comparison, it has been observed that the present results are fairly in good agreement with those from the references. Note that, a bearing reduces to a ordinary gas bearing for compliance coefficient $S=0$. Figure 8 shows the pressure profile of the GFB for $\mathrm{L} / \mathrm{D}=1.0, \Lambda=1.0, \mathrm{~S}=1$ and $\varepsilon$ $=0.6$.

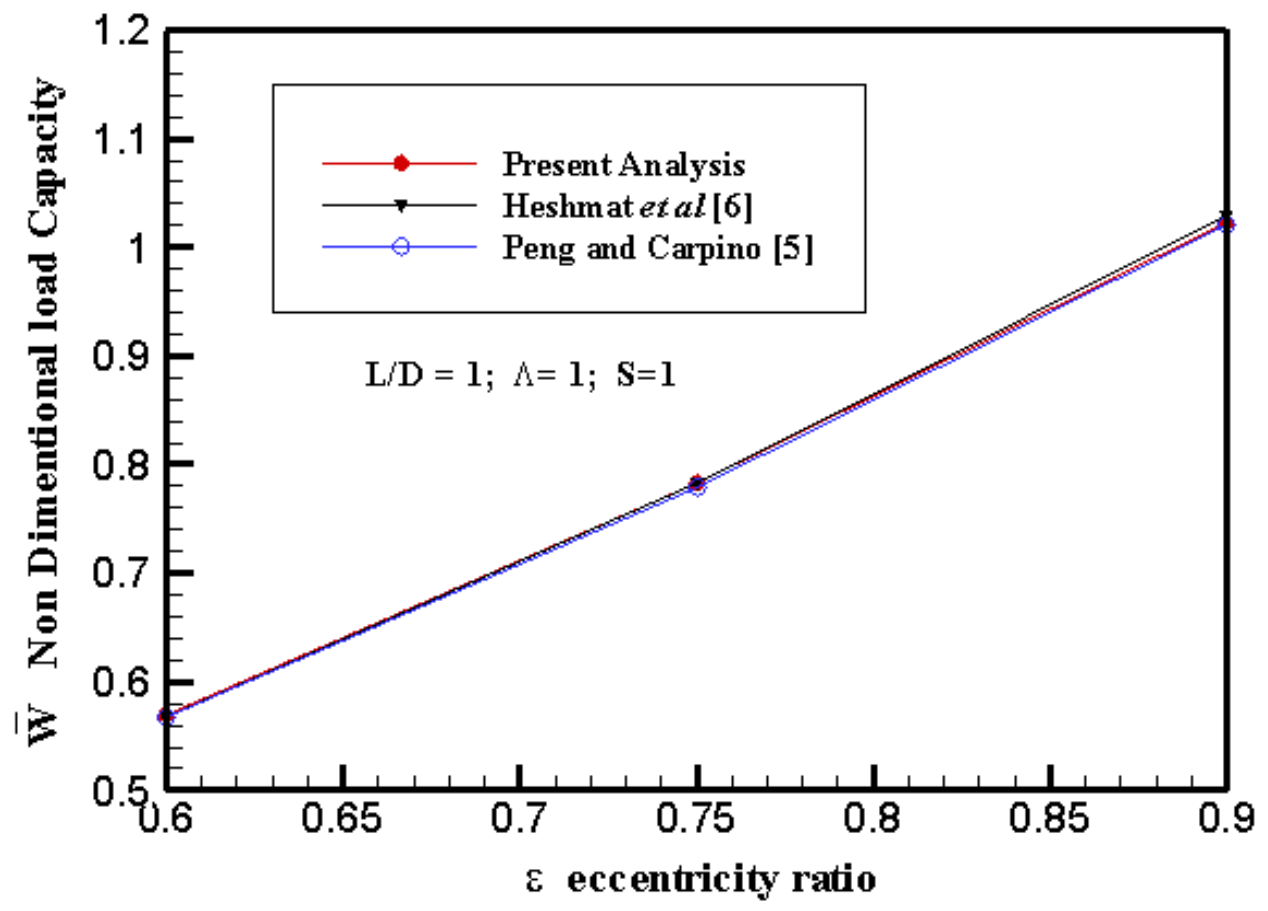

Fig. 6: Validation of load carrying capacity with Heshmat et al [6] and Peng and Carpino[5].

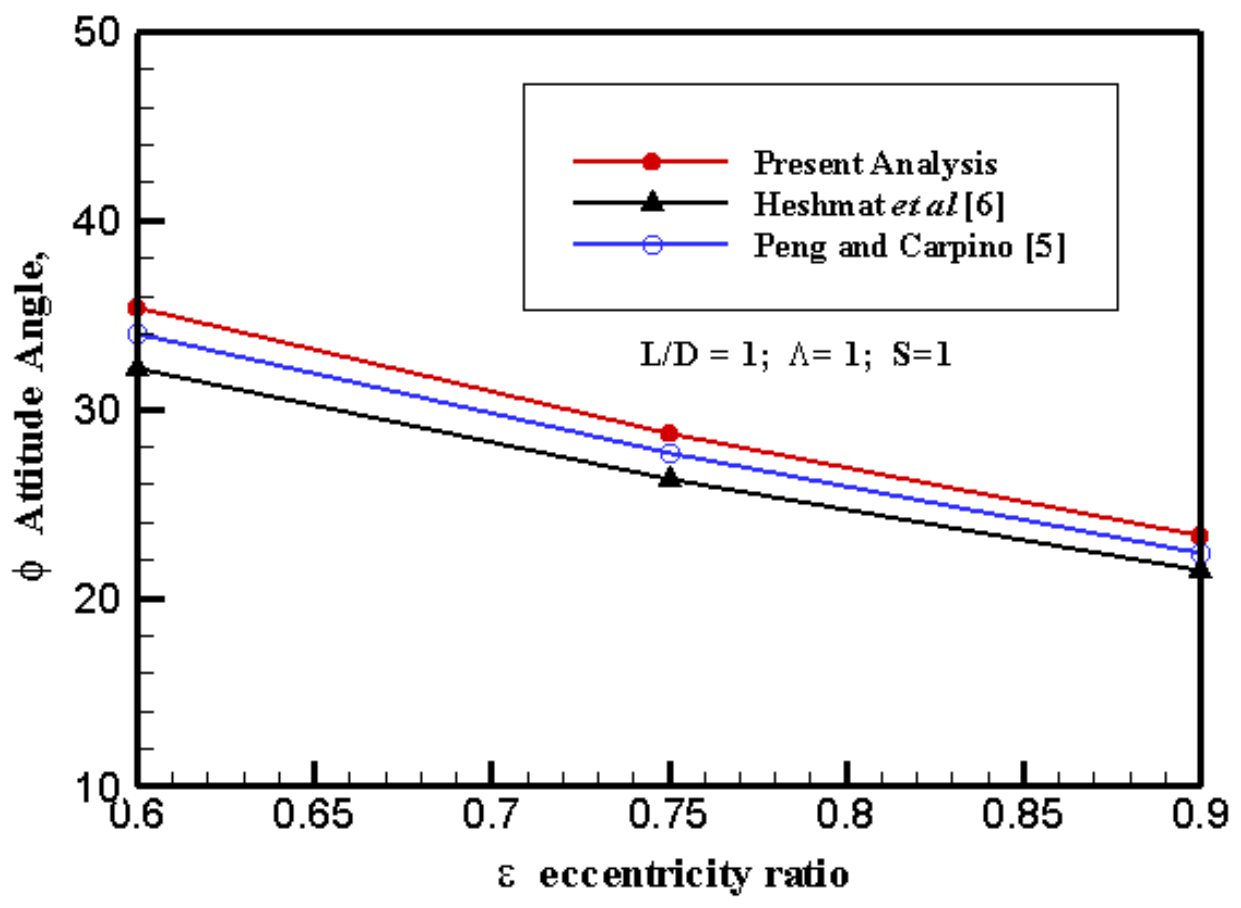


Fig. 7: Validation of attitude angle with Heshmat et al [6] and Peng and Carpino[5].

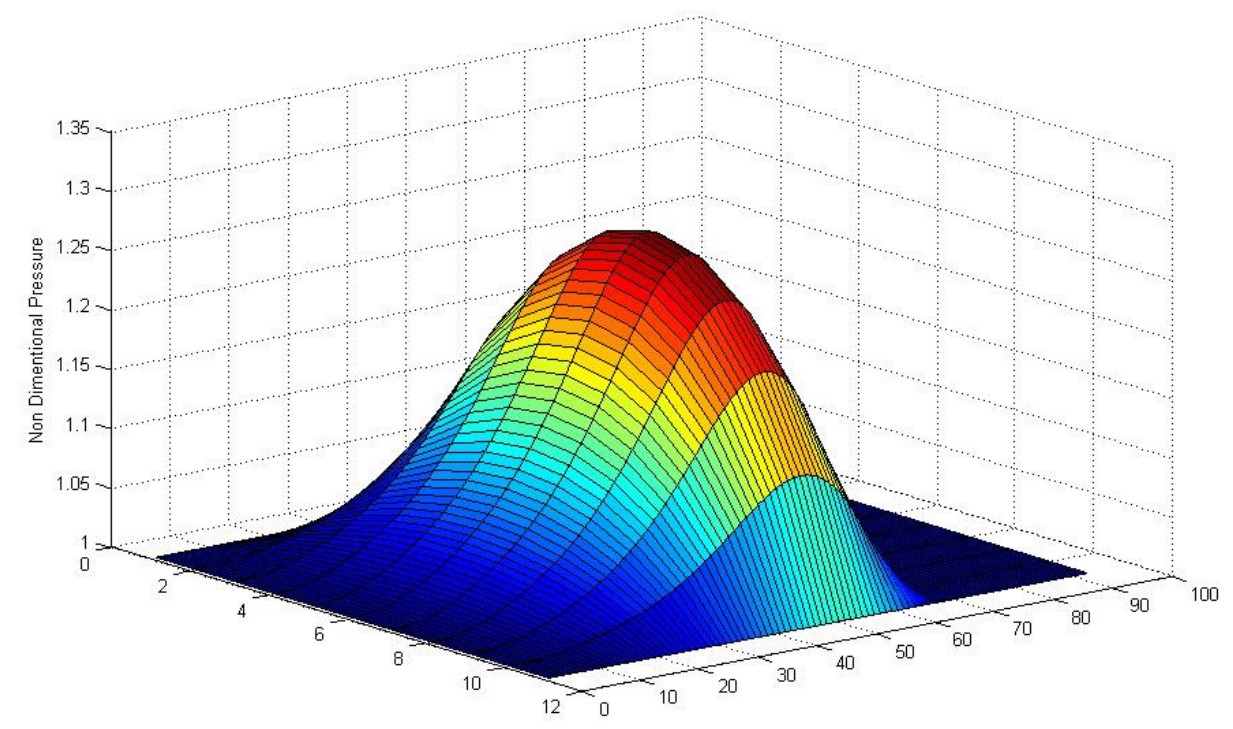

Fig 8: Pressure Profile of GFB for $\mathrm{L} / \mathrm{D}=1.0, \Lambda=1.0, \mathrm{~S}=1$ and $\varepsilon=0.6$

\subsection{Configuration of Test GFB}

Table 2 provides the parameters for the test foil bearing given in [10] and Figure 5 depicts the configuration of the bump foil strip. The foil bearing is a "first generation" type with one $360^{\circ}$ top foil and one bump strip layer, both made of Inconel X-750. The top foil and bump layer are spot welded at one end to the bearing sleeve. The other end of the top foil is free as well as the end of the bump strip layer. The journal rotational direction is from the free end of the top foil towards its fixed end and all tests in were performed with air at ambient condition.

\section{Table 2: Design details of foil bearing, reference [10]}

Bearing radius, $R=D / 2$

Bearing length, $L$

Foil arc circumferential length, $l_{x}$

Radial journal travel, $c_{J}(\sim$ Clearance, $C$ )

Top foil thickness $t_{t}$

Bump foil thickness, $t_{b}$

Bump pitch, $s$

Half bump length, $l_{0}$

Bump height, $h_{b}$

Number of Bumps

Bump foil Young's modulus, $E_{b}$
$19.05 \mathrm{~mm}$

$38.1 \mathrm{~mm}$

$120 \mathrm{~mm}$

$31.8 \mu \mathrm{m}$

$101.6 \mu \mathrm{m}$

$101.6 \mu \mathrm{m}$

$4.572 \mathrm{~mm}$

$1.778 \mathrm{~mm}$

$0.508 \mathrm{~mm}$

26

$214 \mathrm{GPa}$ 


\subsection{Results}

\subsubsection{Effect of Bump Foil Thickness on the Static Performances}

The GFB computational tools for simple elastic foundation model have been developed which predict the static performance of the GFB. The prediction for the simple elastic model uses a mesh of 90 and 10 elements in the circumferential and axial directions respectively. The same mesh size were used for the finite difference numerical scheme solving Reynolds Eqn. (5) and calculating the hydrodynamic gas film pressure.

The bump foils which is a measure of the foil structure has been varies and its characteristics has been observed on the performance of load capacity of the bearing.

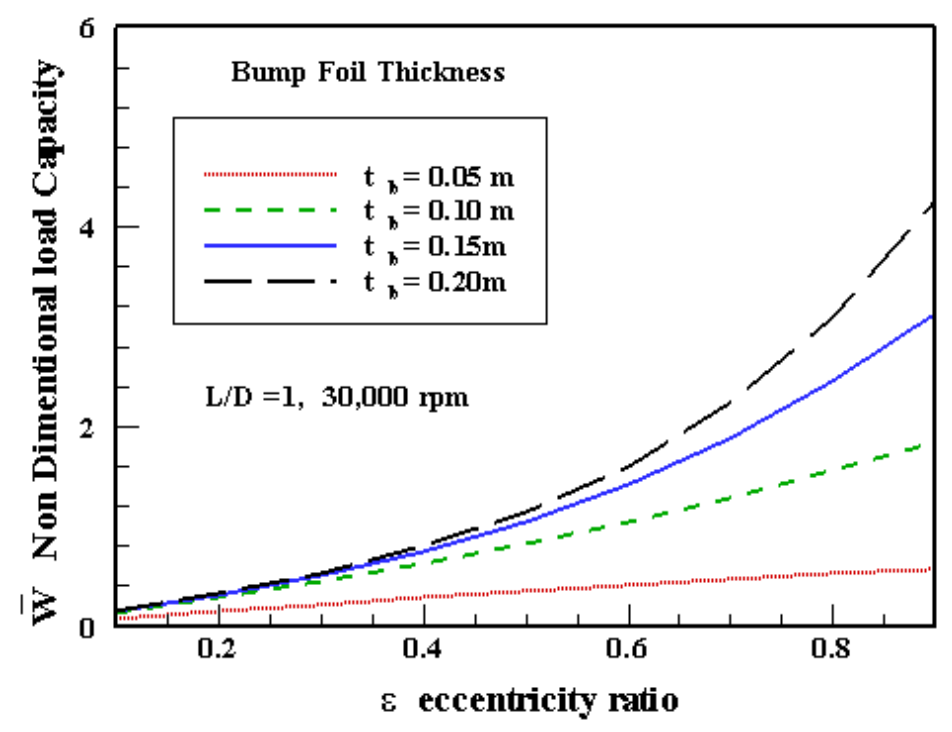

(a) 


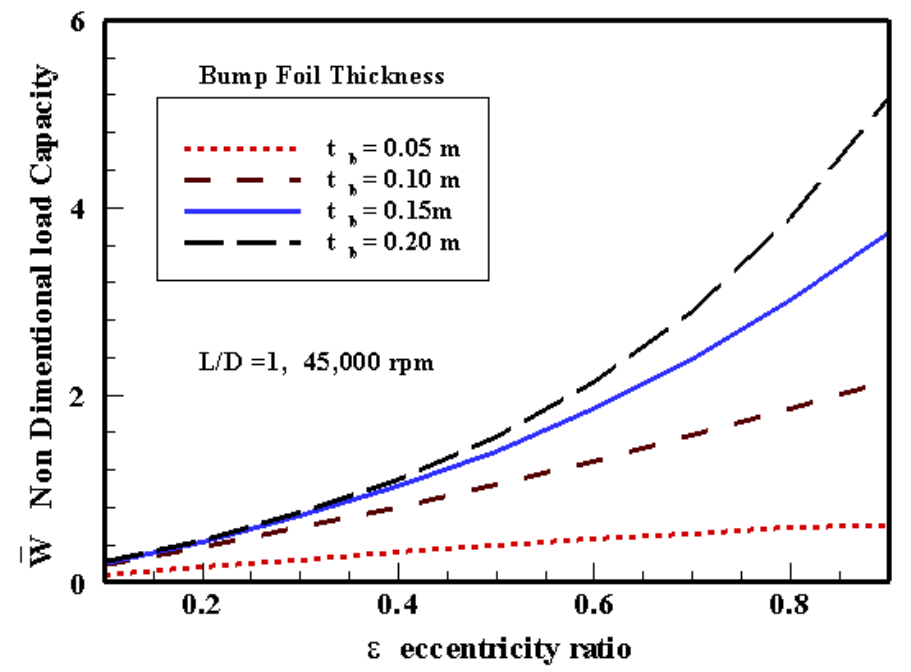

(b)

Fig 9: Effect of bump foil thickness on the load carrying capacity of GFBs at different eccentricity when the rotating velocity is (a) 30,000 rpm and (b) 45,000 rpm

Figure 9 (a) and (b) shows the prediction of the load carrying capacity for various bump foil thickness at different eccentricity ratios and at the rotating velocity of 30,000 rpm and 45,000 rpm respectively. As the eccentricity increases, the load capacity increase linearly for all values of bump foil thickness, which becomes significant at higher eccentricity ratios and at higher rpm. The increase though is not so prominent for smaller bump foil thickness at $t_{b}=0.05 \mu \mathrm{m}$ compared to higher foil thickness at $t_{b}=0.20 \mu \mathrm{m}$ operating at different speed which is eminent from figure 9 (a) and (b). These results hence indicate that too thin a bump foil thickness can lead to a significant decrease in the load capacity due to the excessive foil structure deflection. In addition, a large increment of the load capacity from variation of the foil stiffness may not be expected under a simple foil structure.

\subsubsection{Effect of number of bumps and bump compliance coefficient on the load carrying capacity of GFBs}

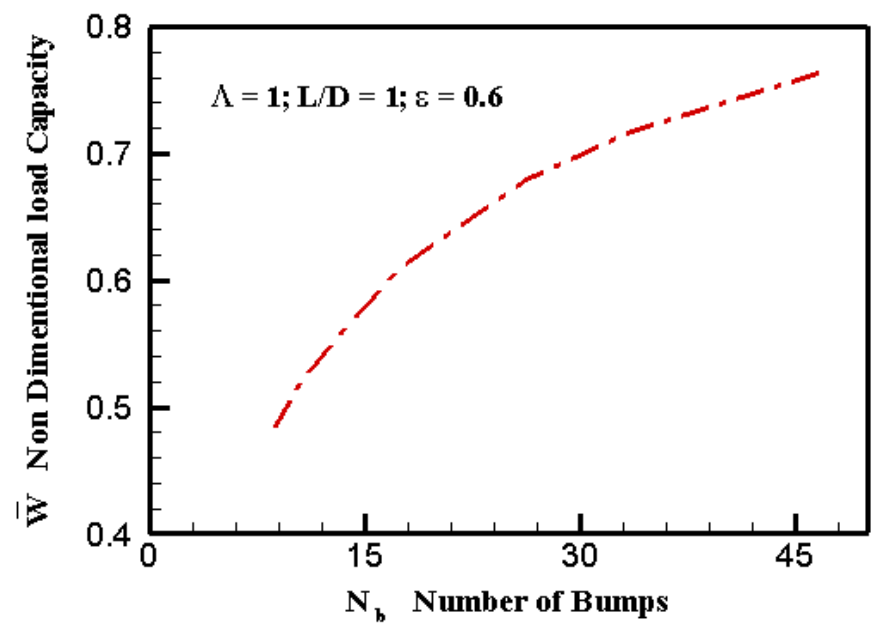

Fig 10: Number of bumps versus load carrying capacity of GFBs 


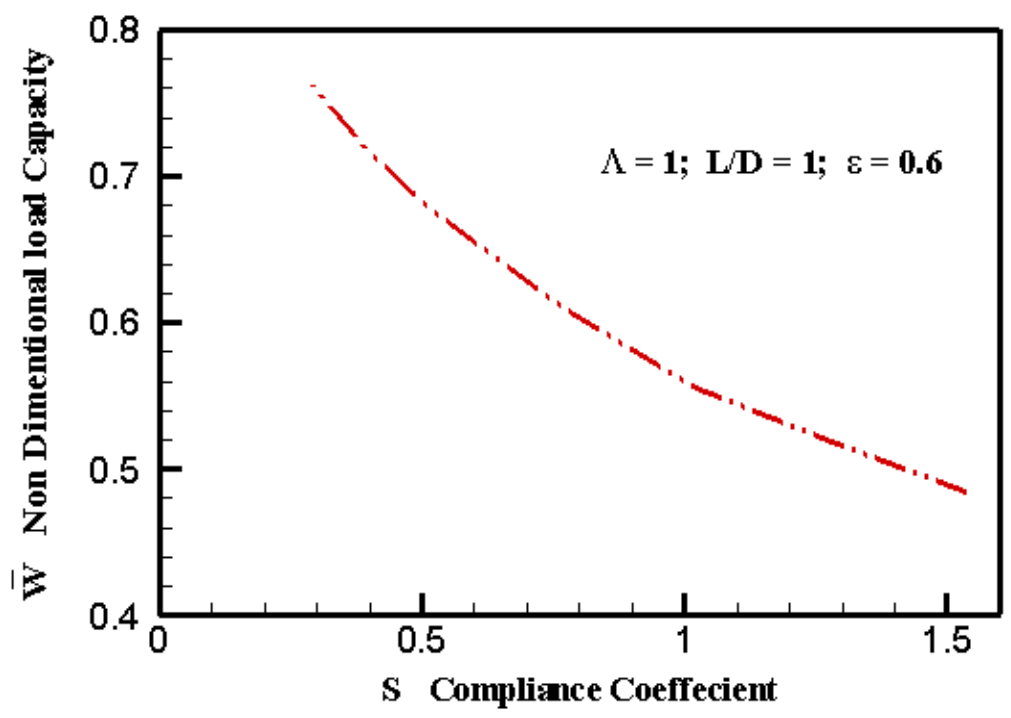

Fig 11: Compliance coefficient versus load carrying capacity of GFBs

Figure 10 depicts the variation of the load capacity of the bearing as the number of bump foils varies. The number of bumps are calculated by dividing the foil arc circumferential length $\left(l_{x}\right)$ by the bump pitch $(s)$, and as the bump number increases the bumps become more crowded and stiffer which resulted in an increase in the load capacity of the bearing as depicted from fig. 10 . The effect of compliance coefficient $(S)$ which is a function of the bump compliance, on the load capacity has been portrait in figure 11 . The load capacity generally decreases as the compliance coefficient increases, which predicts that as the bumps compliance increases the stiffness tends to decrease, as bump compliance is the inverse of stiffness hence a decrease in the load performances of the bearing is eminent.

\section{CONCLUSION}

In this study, a simple elastic foundation model of the foil has been considered where in the stiffness of the bump strip are uniformly distributed throughout the bearing surface, i.e. the bump strip is regarded as a uniform elastic foundation and constant, independent of the actual bump deflection and are not related to or constrained by adjacent bumps. Also the top foil does not sag between adjacent bumps and does not have either bending or membrane stiffness and its deflection follows that of the bump. A numerical model is then developed in order to find out the performance characteristics of the gas foil bearings. The finite difference scheme has been used to discretize the governing Reynolds equation and the pressures are calculated by solving a nonlinear matrix equation using Newton-Raphson technique and the effects of bump foil thickness, number of bumps and bump compliance coefficient on the foil bearing static performances were evaluated. The results of the study show that too thin bump foil thickness may lead to a significant decrease in the load capacity. However for accurate predictions of the foil bearing performances, the present computational analysis can be further extended by incorporating 1D and $2 \mathrm{D}$ finite element model of the foil considering the deflection of the top foil as well as the bump foils. 
International Journal of Recent advances in Mechanical Engineering (IJMECH) Vol.3, No.3, August 2014

\section{REFERENCES}

[1] Heshmat, H., Shapiro, W., and Gray, S., 1982, "Development of Foil Journal Bearings for High Load Capacity and High Speed Whirl Stability,” ASME J. Lubr. Technol., 104, pp. 149-156.

[2] Heshmat, H., 1994, "Advancements in the Performance of Aerodynamic Foil Journal Bearings: High Speed and Load Capability,” ASME J. Tribol., 116, pp. 287-295.

[3] Heshmat, H., 2000, "Operation of Foil Bearings Beyond the Bending Critical Mode," ASME J. Tribol., 122, pp. 192-198.

[4] Lee, Y. B., Kim, T. H., Kim, C. H., Lee, N. S., and Choi, D. H., 2004, "Dynamic Characteristics of a Flexible Rotor System Supported by a Vis-coelastic Foil Bearing,” Tribol. Int., 37, pp. 679-687

[5] Walowit, J. A., and Anno, J. N., 1975, "Modern Development of Lubrication Mechanics" Applied Science, London, Chap. 7.

[6] Heshmat, H., Walowit, J. A., and Pinkus, O., 1983, "Analysis of Gas Lubricated Foil Journal Bearings" ASME J. Lubr. Technol., 105, pp. 647-655

[7] Ku, C. P., and Heshmat, H. 1992, "Complaint Foil Bearing Structural Stiffness Analysis Part I: Theoretical Model-Including Strip and Variable Bump Foil Geometry” ASME J. Tribol. 114. pp. 394-400.

[8] Ku, C. P., and Heshmat, H., 1993, "Complaint Foil Bearing Structural Stiffness Analysis Part II: Experimental Investigation” ASME J. Tribol. 113, pp. 364-369

[9] Rubio, D., and San Andrés, L., 2004, "Bump-Type Foil Bearing Structural Stiffness: Experiments and Predictions" ASME Paper GT 2004-53611

[10] Ruscitto, D., McCormick, J., and Gray, S., 1978, "Hydrodynamic Air Lubricated Compliant Surface Bearing for an Automotive Gas Turbine Engine" I-Journal Bearing Performance. NASA CR-135368.

[11] Lee, D., Kim, Y., and Kim. K., 2008, “The Static Performance Analysis of foil journal bearings considering three-dimensional shape of the foil structure" ASME J. of Tribol. 130/031102

[12] Lee, Y., Park, D., Kim, C., Kim, S., 2008, "Operating characteristics of the bump foil journal bearings with top foil bending phenomenon and correlation among bump foils" Tribol. Int., 41, pp. 221-233.

[13] Kim, T. H., and San Andrés, L., 2008, "Heavily Loaded Gas Foil Bearings: A Model Anchored to Test Data” ASME J.Eng Gas Turb Power. 130. pp. 012504.

[14] San Andrés, L., and Kim, T., 2009, "Analysis of gas foil bearings integrating FE top foil models". Tribol. Int., 42, pp. 111- 120.

[15] Iordanoff, I., 1999, “Analysis of an Aerodynamic Compliant Foil Thrust Bearing: Method for a Rapid Design” J. Tribol., 121, pp. 816-822.

[16] Koepsel, W., 1977, “Gas Lubricated Foil Bearing Development for Advanced Turbomachines”, U. S. Air Force Aero Propulsion Laboratory, Rep. AFAPL-TR-76-114, Vol. 1, 2.

[17] Carpino, M., and Peng, J. P, 1993, "Theoretical Performance Foil Journal Bearings," presented at the AIAA/SAE/ASME/ASME. 27th Joint Propulsion Conference, paper no. AIAA-91-2105

[18] Andre San Luis, Kim Ho Tae, 2008, "Forced nonlinear response of gas foil bearing supported rotors" Tribology International, 41, pp. 704-715.

\section{NOMENCLATURE}

C Bearing radial clearance $(\mathrm{m})$

$D \quad$ Diameter of journal (m)

$e \quad$ Bearing eccentricity $(\mathrm{m})$

$E_{b} \quad$ Young's modulus for bump foil $\left(\mathrm{N} / \mathrm{m}^{2}\right)$

$E_{t} \quad$ Young's modulus for top foil $\left(\mathrm{N} / \mathrm{m}^{2}\right)$

$h \quad$ Film thickness (m)

$H \quad$ Non-dimensional minimum film thickness

$i, j \quad$ Grid location in circumferential and axial directions of FDM mesh 


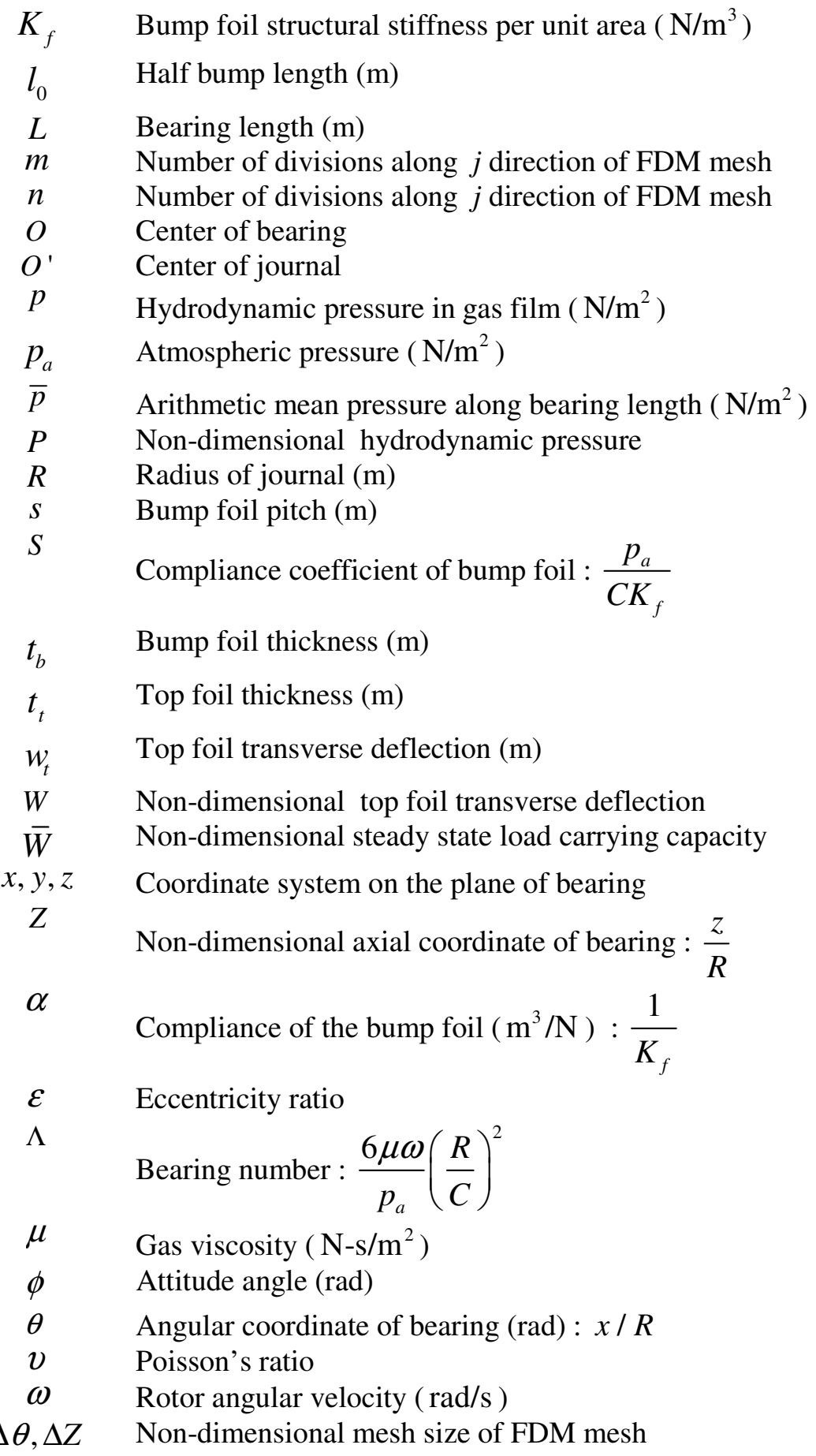


International Journal of Recent advances in Mechanical Engineering (IJMECH) Vol.3, No.3, August 2014

\section{AUTHORS}

1. T. Moasunep Jamir

Research Scholar (PhD)

Department of Mechanical Engineering

Indian Institute of Technology Guwahati

[ sunepbokdi@gmail.com ; t.jamir@iitg.ernet.in

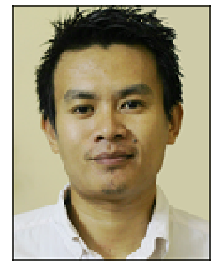

2. Dr. S. K. Kakoty

Professor

Department of Mechanical Engineering

Indian Institute of Technology Guwahati

[sashin@iitg.ernet.in]

\section{Dr. Karuna Kalita}

Assistant Professor

Department of Mechanical Engineering

Indian Institute of Technology Guwahati

[karuna.kalita@iitg.ernet.in] 